\title{
RockGIS: A GIS-based model for the analysis of fragmentation in rockfalls
}

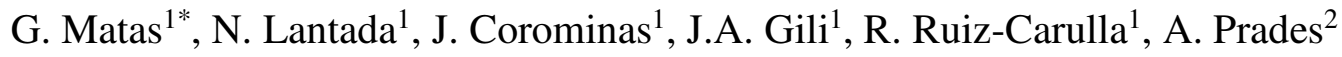

${ }^{1}$ Division of Geotechnical Engineering and Geosciences, Universitat Politècnica de Catalunya. C. Jordi Girona 1-3, 08034 Barcelona, Spain

${ }^{2}$ Division of Geotechnical Engineering and Geosciences, Universitat Politècnica de Catalunya. Dr. Marañón 44-50, 08028 Barcelona, Spain

*Corresponding author. Tel.: +34 9340169 25. Fax.: +34 9340172 51. E-mail address: gerard.matas@upc.edu (G. Matas)

\begin{abstract}
:
A Rockfall is a mass instability event frequently observed in road cuts, open pit mines and quarries, steep slopes and cliffs. After its detachment, the rock mass may disaggregate and break due to the impact with the ground surface, thus producing new rock fragments. The consideration of the fragmentation of the rockfall mass is critical for the calculation of the trajectories of the blocks and the impact energies, for the assessment of the potential damage and the design of protective structures. In this paper, we present RockGIS, a GIS-Based tool that simulates stochastically the fragmentation of the rockfall, based on a lumped mass approach. In RockGIS, the fragmentation is triggered by the disaggregation of the detached rock mass through the pre-existing discontinuities just before the impact with the ground. An energy threshold is defined in order to determine whether the impacting blocks break or not. The distribution of the initial mass between a set of newly generated rock fragments is carried out stochastically following a power law. The trajectories of the new rock fragments are distributed within a cone. The fragmentation model has been calibrated and tested with a 10,000 $\mathrm{m}^{3}$ rockfall that took place in 2011 near Vilanova de Banat, Eastern Pyrenees, Spain.
\end{abstract}

KEYWORDS: Rockfall, fragmentation, GIS, Rockfall simulation

\section{ACKNOWLEDGMENTS}

This work has been funded by Spanish Government (Ministerio de Economia y Competitividad) through the RockRisk research project (BIA2013-42582-P) and the grant to the first author (BES-2014-069795). 


\section{INTRODUCTION}

A rockfall is a rapid mass movement generated by the detachment of a rock volume from the slope that falls, rolls and bounces along its trajectory. This phenomenon may occur singly or in clusters, but there is little dynamic interaction between the moving fragments (Hungr et al. 2014). Despite their relatively small size compared to other mass movements, rockfalls can be very destructive as high velocities and consequently, high energies, can be reached during their propagation downslope (Cruden and Varnes 1996), resulting in a similar order of magnitude of fatalities than bigger mass movements (Hoek 2000). Many rockfall analyses are oriented to the assessment of the damage caused to people, civil infrastructures and buildings as well as to the proper design of mitigation measures. Extended reviews of qualitative and quantitative methodologies for rockfall hazard assessment can be found at Volkwein et al (2011) and Ferrari et al (2016).

There are three main strategies to mitigate the risk from rockfalls (Corominas, 2013): (a) hazard reduction by means of reinforcement and stabilization works; (b) constraining and obstructing the progression of the rockfall mass by means of defense structures with the consequent reduction of its magnitude, velocity, and runout; and (c) protecting the exposed elements. For the latter two options, the kinematics of the blocks such as the kinetic energy, velocity, passing height and reach probability must be estimated at the exposed areas. Modern techniques for determining these values use computational simulations for performing trajectory analyses of rockfalls.

Rockfall models simulate the kinematics of the boulders, calculating their movement downslope using Newton's second law neglecting air friction. Some of these models also include explicitly the rolling motion of blocks (Agliardi and Crosta, 2003; Lan et al., 2007), but the study of the interaction of the blocks with the topographic surface during the successive contacts (impacts) is the main scientific challenge in rockfall modelling (Bourrier and Hungr, 2011). Propagation models can be classified by how they simplify reality and the hypotheses they consider with respect to the following aspects:

- Spatial dimension: The calculation of the trajectories can be performed in a 2D (Van Dijke and van Westen, 1990; Meissl, 1998) or 3D space (Agliardi and Crosta, 2003; Dorren et al 2005; Lan et al., 2007; Leine et al., 2013; Gischig et al., 2015). Some models use a 2.5D approach (Dorren and Seijmonsbergen, 2003) in which the slope profiles required for performing the $2 \mathrm{D}$ analysis are obtained from Digital Elevation Models using algorithms like the maximum slope path for determining the possible propagation direction of rockfalls.

- Block kinematics: The kinematics of falling rocks can be described as rolling, sliding and bouncing over the substratum (Ritchie, 1963). However, it is not always necessary to account for all of them to simulate rockfalls, and each model considers different combinations of these types of motion. The kinematics of the blocks is closely related to the shape considered in each model.

- Block shape: The shape of the blocks can be explicitly accounted for (rigid body approach) or simplified by treating all the mass of the block as concentrated in one point (lumped mass approach). In the rigid body approach the shape of the blocks can be considered as a sphere or a cylinder, as a 3D mesh (Leine et al., 2013), or as a combination of spheres using the Discrete Element Method (DEM) (Giacomini et al., 2012; Paluszny et al.,2016). Some models consider a combination of both approximations at different stages of the calculation process (hybrid approach). Examples of models using these different approaches are shown in Volkwein et al. (2011).

- Impact modelling: Impact detection routines depend on the block shape considered and once the impact with the ground is detected, a rebound model is applied in order to estimate the post-impact velocity of the block. There are several rebound models, from simpler ones that consider only a percentage loss of the velocity with respect to a local coordinate system at the impact point, to the ones that account for the mechanical properties of the ground, impact angle, angular velocity, block size, etc. (di Prisco and Vecchiotti, 2006). A review of the different existing rebound models can be found in Bourrier and Hungr (2011). Some models also consider impacts with trees (Dorren et al 2005; Dupire et al. 2016) or mitigation structures such as fences and ditches using specific impact models (Lambert et al. 2013).

- Dealing with uncertainty: Every impact of a rock particle is a random process (Bourrier et al. 2009). There are many sources of randomness when performing numerical rockfall analyses, such as the source location, the rock properties, the initial kinematic conditions, the slope properties during impacts, etc. Li and Lan (2015) present an exhaustive review of how existing models deal with uncertainties.

A compilation of the common practices in rockfall numerical modelling and a classification of the existing models is found in Volkwein et al. (2011). More recently, in the field of rockfall propagation modelling, Gischig et al. (2015) proposed a new 3D model that includes a different methodology that considers hyperbolic restitution factors. Additionally, new commercial software has been launched (i.e. RockPro3DC and GeoRock3DC).

Considering the blocks unbreakable during their propagation is a common hypothesis in most of the existing propagation models ( $\mathrm{Li}$ and Lan, 2015). However, fragmentation is a process frequently observed in rockfalls and it is defined as the separation of the initial rock mass into smaller pieces upon impact with the ground (Evans and Hungr, 
1993). This definition covers both the disaggregation of the block fragments delimited by pre-existing fractures in the initial mass and the generation of new fragments due to the breakage of intact rock (Corominas et al. 2012).

The fragmentation mechanism is considered to be the most complicated and the least understood process in rockfall propagation (Giacomini et al. 2009) and very few contributions address this topic specifically. Two main consequences of the fragmentation are the generation of multiple fragments and the divergence of the fragment trajectories downhill from the impact point. After an impact involving fragmentation, the initial rock mass generates a number of block fragments that can be characterized by a volume distribution (Ruiz-Carulla et al. 2015a). Further features are higher bounces, higher post-impact velocities (Agliardi and Crosta, 2003) and the ejection of small fragments. These physical effects may change significantly the way rockfalls interact with the terrain, the defense structures and the exposed buildings.

The resultant fragments propagate downslope following independent trajectories, which is crucial for the trajectory analyses and for hazard assessment. The simulation of the trajectories of a rockfall with or without considering the fragmentation may differ notably. Furthermore, analyses which ignore fragmentation tend to overestimate both the kinetic energy and runout. On the other hand, the probability of an impact with exposed elements is largely underestimated because the blocks generated during fragmentation define multiple trajectories (Corominas et al. 2012). The possibility of multiple impacts with fences or buildings due to the increased number of blocks may be added to the list of possible fragmentation consequences.

The main objective of this contribution is to present a GIS-based code that accounts for fragmentation in the stochastic simulation of rockfalls. The conceptual framework for developing the fragmentation model is described in section 3 and it is supported by several real scale tests carried out in a quarry (Gili et al., 2016). The model has been tested on a real rockfall event near Vilanova de Banat hamlet in the Cadí Sierra, Eastern Pyrenees, Spain. The results and their analysis are presented in section 4.

\section{FRAGMENTATION MODELLING IN ROCKFALLS}

For a better understanding of the fragmentation phenomenon, some authors have used energetic considerations in attempts to understand the effect of the loading rate on the rockfall breakage (Grady 1987, Zhang et al, 2000). Giacomini et al. (2009) performed several fragmentation field tests with emphasis on the influence of the impact angle in case of foliated materials. In the cited study, the idea of an impact energy threshold to trigger breakage of the blocks proposed by Fornaro et al. (1990) was not confirmed. Recently, Gili et al. (2016) performed several rockfall fragmentation field tests in which this concept of an energy threshold was not observed either, but a correlation of the number of blocks generated during breakage and the fractal dimension of the generated volumetric distribution was found (Ruiz-Carulla et al., 2016b).

Some approaches have modelled the disaggregation of block masses defined by pre-existing discontinuities using DEM in 2D (Salciarini et al., 2009) and in 3D (Cuervo, 2015). These models require defining pre-existing discontinuities of the masses and simulated the interaction between the different fragments using a rigid body approach.

In order to model breakage, Fornaro et al. (1990) defined an energy threshold, based on experimental results in Mancini et al (1981), from which the block was randomly divided into several small fragments and the kinetic energy was distributed proportionally to each fragment volume. Wang and Tonon (2011) used neural networks that statistically reproduce the fragmentation of a block on impact with the ground surface using data from DEM simulations. In this case, a limited set of fracture orientation and impact angle configurations was considered during the simulations for generating the neural network. The breakage model developed by Wang and Tonon (2011) was implemented in HyStone rockfall propagation code (Crosta and Agliardi, 2003) and tested in a real case in Frattini et al. 2012. Paluszny et al. (2016) have proposed a direct fragmentation method to break blocks so that the volumetric distribution of the generated fragments fits a Weibull distribution in DEM simulations without simulating de-bonding or crack propagation, thereby reducing the computational cost by avoiding re-meshing and re-creating the solid geometry during the simulation. 


\section{CONCEPTUAL FRAGMENTATION FRAMEWORK}

A kinematically unstable rock mass detached from a slope can be a massive block or a set of blocks of intact rock delimited by pre-existing discontinuities depending on the fracture pattern. The size range of the blocks is characterized by the In Situ Block Size Distribution (IBSD). During the propagation of the mass downslope, the original distribution may be modified by the disaggregation of the rock mass along pre-existing discontinuities and the breakage of intact rock. The resulting distribution after the fragmentation, including disaggregation and breakage, is the Rockfall Block Size Distribution (RBSD) (Hantz et al. 2014, Ruiz-Carulla et al. 2015a). Fig. 1 shows this process schematically.

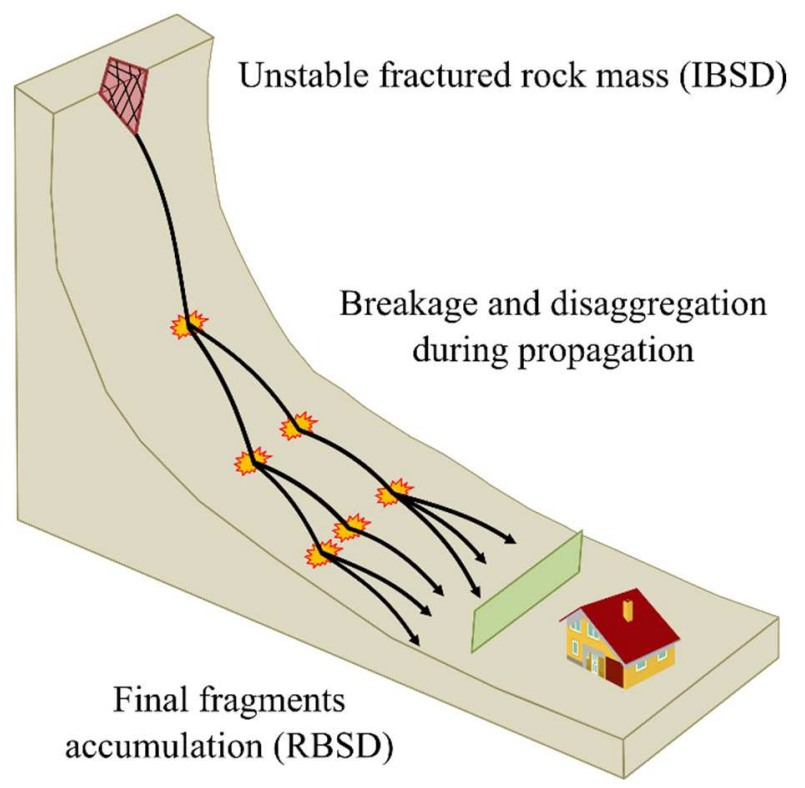

Fig. 1. Fragmentary rockfall phenomenon. When the fractured rock mass is detached, it moves downslope and may fragment during the impacts with the ground surface.

In this work we present and implement a stochastic approach for considering fragmentation phenomena in common GIS-based lumped-mass models assuming a simple hypothesis that can be easily modelled and fitted to field data. Agreeing with Gischig et al. (2015), we consider that randomness is the main characteristic of rockfall impacts and, consequently, of the fragmentation process. Therefore, we focus on the volumetric variations that the IBSD experiences during the propagation of the detached mass so as to be able to simulate the process globally and obtain a final RBSD that fits the field observations. The following paragraphs describe the fragmentation model and how it has been implemented.

As explained in the introduction, the rockfall propagation codes simulate the trajectories of the blocks using a combination of the three possible modes of motion. In Fig. 2, the diagram used for the simulation of an individual block and the proposed implementation of the fragmentation model is shown. For reasons of simplicity, only flying, bouncing and rolling motions have been included in the diagram as they are the ones usually taken into account. The cells in blue are the steps to include in these algorithms to consider fragmentation (both disaggregation and breakage).

The proposed model assumes that the disaggregation of all the blocks forming the ISBD occurs at the moment of the detachment from the rock slope. No energy is required for the disaggregation of the ISBD. With this assumption, all the blocks with their corresponding volumes are simulated individually. Collisions between blocks are not considered along the path. Therefore, to run the model it is necessary to define an initial rock mass volume, which contains a set of rock blocks characterized by the IBSD (Fig. 2). 


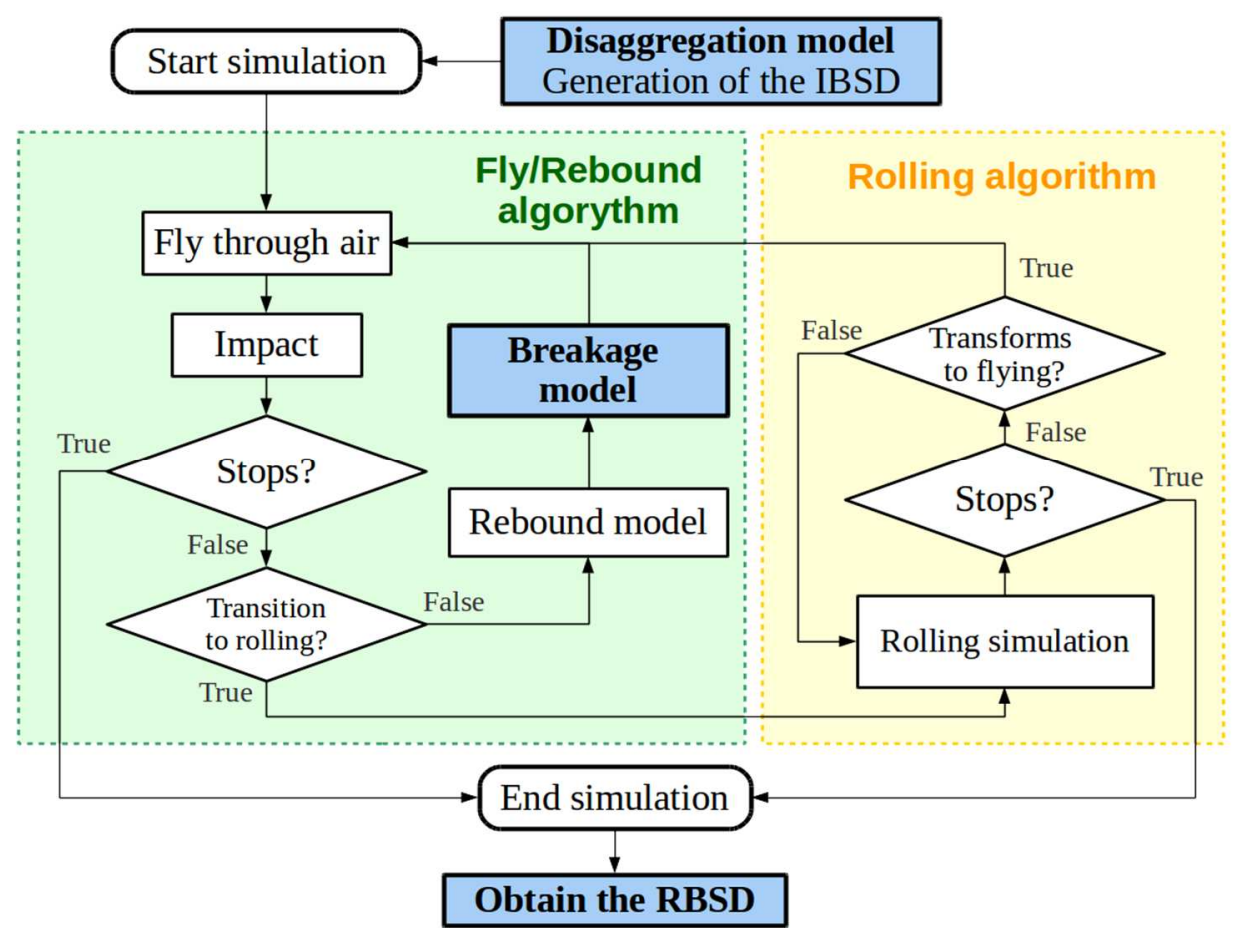

Fig. 2. GIS-Based tool flowchart for an individual block simulation. Within the global process of detachment and propagation, the steps marked in blue account for fragmentation.

The conservation of energy during a fragmentary impact can be written as follows in Equation 1 (Giacomini et al. 2009):

$$
E_{k}^{b i}=E_{k}^{a i}+E_{d}+E_{b} \quad(\text { Equation } 1)
$$

where $E_{k}^{b i}$ is the kinetic energy before impact, $E_{d}$ is the energy dissipated in the impact with the ground, $E_{b}$ is the energy dissipated due to the breakage process and $E_{k}^{a i}$ is the sum of each fragment's kinetic energy.

The main hypothesis of our breakage model is to consider the energy loss from the impact of the block with the ground and the energy released during its breakage as uncoupled processes. This means that we can consider that the breakage of the block will occur after the computation of the rebound velocity, independently of the rebound model used.

Studies of rock mass fragmentation upon impacts have found that the proportion of impact energy dissipated during breakage is roughly constant (Giacomini et al. 2009). In our model a simple coefficient of breakage energy loss, $C_{b}$, has been considered for computing $E_{b}$ (Equation 2). In the event of breakage, the energy loss is applied after the computation of the rebound and its inherent energy loss $E_{d}$, controlled by the coefficients of restitution.

$$
E_{b}=C_{b} \cdot E_{k}^{b i} \quad(\text { Equation 2) }
$$

Our model requires determining whether breakage will or will not occur after each impact with the ground, the amount of energy consumed by the fragmentation process, the number and size of the fragments produced, how the remaining energy is distributed among the fragments and finally, the output trajectories for each fragment. Fig. 3 shows a flowchart with the steps of the breakage model proposed, and the next sections explain the details of each step of the process. 


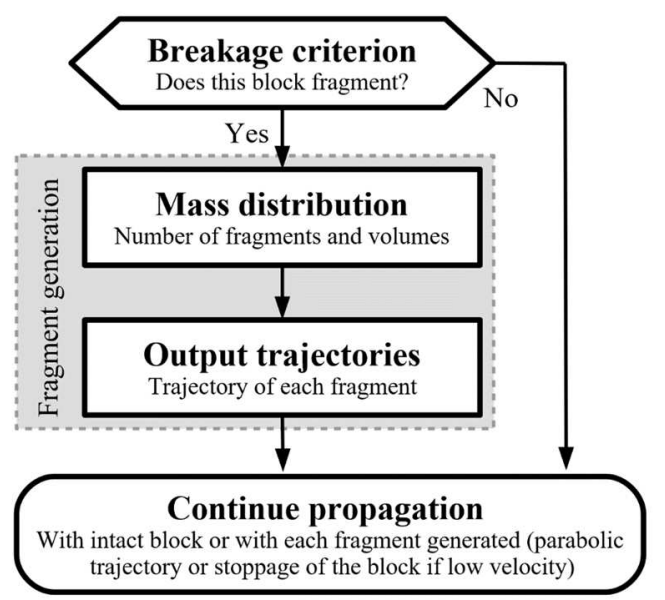

Fig. 3. Flowchart with all steps of the breakage process used in the model in Fig. 2.

The proposed model has been implemented into a GIS-based tool named RockGIS, which simulates the rockfall trajectories along the slope including a fragmentation module. The first version of the code has been written using Python programming language. The inputs required for the simulation are a Digital Elevation Model of the slope and the surface material coverage as raster files and the definition of the rockfall sources (detachment coordinates, number of blocks, volumes and initial velocities). RockGIS uses a lumped mass approach and simulates the trajectory of each block using Newton's second law, a simple rebound model (described in the following sections), and neglects air friction. In this first version of the code, rolling is not accounted for. At each impact the fragmentation module determines whether the block breaks and if so, all fragments generated start their own propagation as if they were new blocks.

\subsection{Impact and rebound model}

In lumped mass models the block rebound is usually defined by normal $R_{n}$ and tangential $R_{t}$ restitution coefficients (Equation 3) that describe the decrease in the normal and tangential velocities after impact (Volkwein et al., 2011).

$$
R_{n}=\frac{V_{n}^{+}}{V_{n}^{-}} \text {and } R_{t}=\frac{V_{t}^{+}}{V_{t}^{-}} \quad(\text { Equation } 3)
$$

where $V_{n}^{-}$and $V_{t}^{-}$are the normal and tangential velocities of the block before the rebound and $V_{n}^{+}$and $V_{t}^{+}$are the velocities after the rebound.

Given a land coverage, in the RockGIS model the restitution coefficients are not constant but vary slightly according to the size of the block. The higher the size of the block, the higher the coefficients of restitution. Additionally, these values are stochastically perturbed.

\subsection{Breakage criterion}

The breakage criterion determines whether a block breaks or not during the impact. In the RockGIS model it is defined as the impact kinetic energy threshold. This concept was proposed by Fornaro et al. (1990). As a first approximation, the more energetic the impact, the higher the probability of breakage. A survival rate ranging from 0 to 1 may be accounted for statistically, allowing a percentage of blocks to survive despite having reached the breakage energy threshold (see equation 4). This criterion is simple, as other factors such as the relative orientation of internal fractures of the block might have much more influence on the fragmentation (Giacomini et al. 2009). However, in a lumped mass approach the relative orientation of the internal fractures of the block with the impact direction is not accounted for. This limitation of the lumped mass approach is indirectly overcome by incorporating a random formulation in the breakage criterion using a probability of breakage $\left(P_{b r}\right)$ that will allow a certain percentage of the blocks to survive although they have reached the energy threshold during an impact.

$$
E_{k}^{b i}>E_{\text {threshold }} \text { and } P_{b r}<\text { random }[0,1] \Rightarrow \text { Breakage } \quad \text { (Equation 4) }
$$

The distribution of the mass of the impacting block between the fragments generated follows a power law (equation 5). The idea of using power laws for distributing the mass after breakage comes from a series of real-scale tests carried out in a quarry (Gili et al. 2016) to improve the understanding of the fragmentation process, and from fractal distribution models studied by Ruiz-Carulla et al. (2015b). In these tests, a total of 56 blocks with volumes ranging from 0.2 to 4.8 $\mathrm{m}^{3}$ were tested in a limestone quarry. Regarding the results of these tests, the distribution of the mass among the fragments resulting from the breakage may be estimated by a power law. 


$$
P_{i}=c \cdot V^{-b} \quad(\text { Equation 5) }
$$

Where $c$ and $b$ are the parameters that define the shape of the power law, $V$ is the volume of the blocks in cubic meters and $P_{i}$ is the relative cumulative frequency. Fig. 4 shows three examples of the volumetric distributions obtained after the breakage of three blocks and their corresponding power laws adjusted using least squares. With this adjustment, $b$ and $c$ can be obtained by back-analysis from the field data.

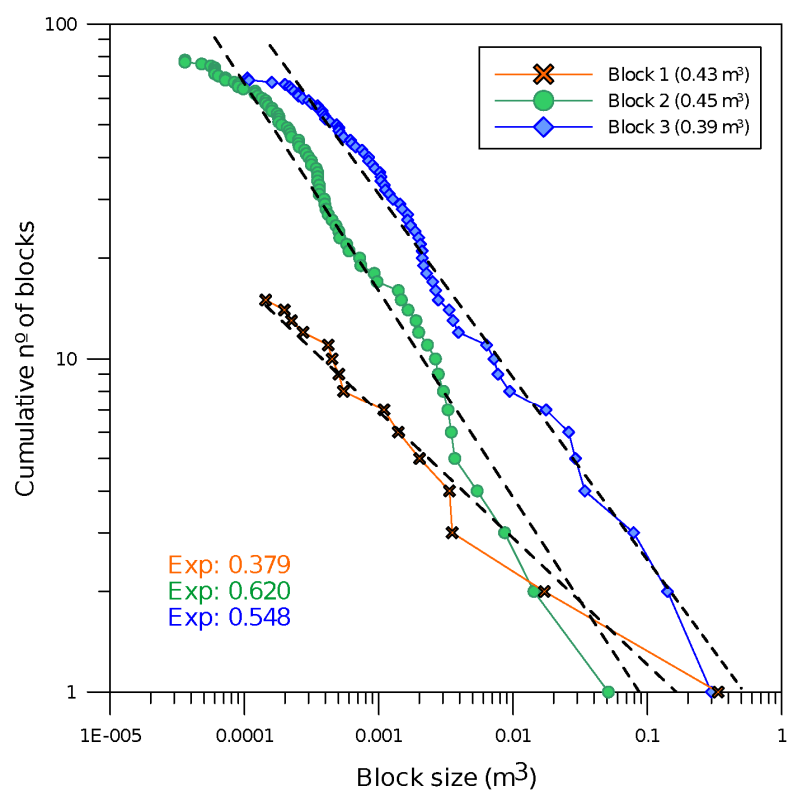

Fig. 4. Example of three cumulative fragment distributions measured after the breakage of the blocks. The volume of each initial block and the exponent corresponding to the adjusted power law of the generated distributions are shown.

Once the breakage criterion is fulfilled, random fragments are generated following a power law until the sum of all their volumes equals the initial volume of the impacting block. We have followed the iterative process described in Moya et al. (2013), but any other methodology for generating the fragment distribution could be used. Equation 6 shows the inverted power law equation used for generating the volume of each fragment during an iteration, and Equation 7 the condition for stopping the fragment generation process when volume conservation is reached. In both equations, $V_{i}$ is the volume of the computed fragment, $V_{0}$ is the initial volume of the block, $c$ and $b$ define the shape of the power law used and $n$ is the number of fragments generated. $R_{i}$ are random numbers used to generate a stochastic set of fragments.

$$
\begin{gathered}
V_{i}=\left(\frac{c}{R_{i}}\right)^{\frac{1}{b}} \text { where } R_{i} \in \operatorname{random}[0,1] \quad \text { (Equation 6) } \\
n: \sum_{n} v_{i}=V_{0} \text { if } \sum_{n} v_{i}>V_{0} \Rightarrow V_{n}=V_{0}-\sum_{n-1} v_{i} \quad \text { (Equation 7) }
\end{gathered}
$$

The coefficients $c$ and $b$ of the power law have to be estimated. As a first approximation, average values have been back-analyzed from the test carried out in Gili et al. (2016).

A number of options exist in order to distribute the energy among the new fragments. The conservation of energy and momentum must be satisfied. After the energy loss due to breakage, the fragment velocities have to follow Equation 8 .

$$
\frac{1}{2} m_{0} v_{0}^{2}=\sum_{i} \frac{1}{2} m_{i} v_{i}^{2} \quad(\text { Equation } 8)
$$

where $m_{0}$ and $v_{0}$ are the mass of the block and its velocity before breakage respectively and $m_{i}$ and $v_{i}$ are the masses and velocities of each generated block after fragmentation.

\subsection{Fragment trajectories}

The post-impact trajectory of each fragment is assumed to stay within the boundaries of a cone (Fig. 5). The revolution axis of the cone follows the direction of the outcome velocity computed by the rebound model and the fragments generated follow random trajectories within the cone. The aperture of the cone is defined by the angle $\theta$. The numerical implementation of this method requires the generation of random unitary vectors inside the cone, a change of the reference system to correlate the revolution axis of the cone with the expected outcome velocity, and finally a multiplication of each vector for the computed outcome velocity of each fragment. 


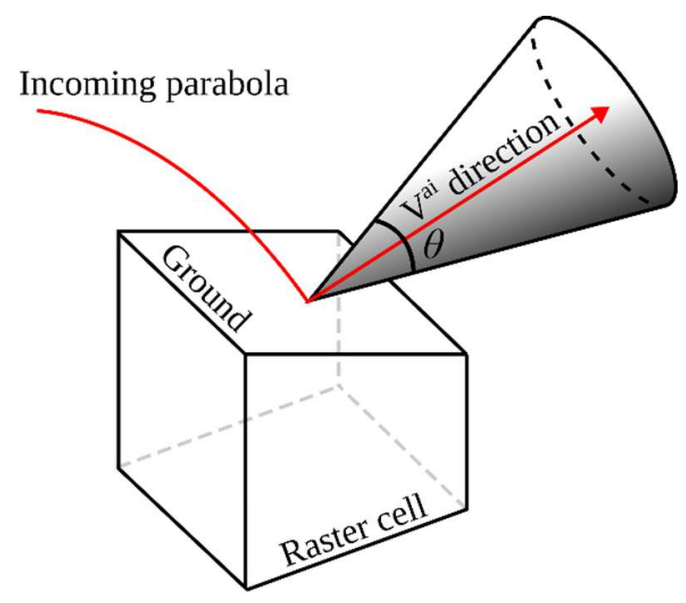

Fig. 5. Cone envelope of all the possible trajectories of each rock fragment after a fragmentary impact. The revolution axis follows the direction of the computed velocity after the impact $V^{a i}$.

\section{CASE STUDY: Vilanova de Banat rockfall}

\subsection{Data}

The proposed fragmentation model has been tested with a fragmental rockfall event which occurred on a limestone cliff in the Cadí Sierra, Eastern Pyrenees near the village Vilanova de Banat in November 2011. Previous studies of this event (Ruiz-Carulla, et al., 2015a) estimated the initial detached mass to be10,000 $\mathrm{m}^{3}$, the source area 40 meters in width and 40 in height (from $2270 \mathrm{~m}$ to $2310 \mathrm{~m}$ of altitude), the thickness 14 meters and the shape a wedge. This mass produced several fragments during its propagation downslope, generating a Young Debris Cover (YDC) that covered an area of approximately 30,000m² over altitudes of 1950 - 2138 m. Some Large Scattered Blocks (LSB) where observed to have a higher runout than the YDC. According to Ruiz-Carulla et al. (2015a), it is assumed that all the blocks progressed downslope following independent paths since no debris stream features, which are typical of rock avalanches (Hungr et al. 2014), were found.

In Ruiz-Carulla et al. (2015b) the Rockfall Block Size Distribution (RBSD) of this event was obtained by taking measurements in representative sampling plots within the young debris cover (YDC). Systematic measuring of the large scattered blocks was also carried out. In the cited work, the In Situ Block Size Distribution (IBSD) was extracted from a Discrete Fracture Network generated using a Digital Surface Model of the cliff prior to the failure, obtained with digital photogrammetry. This IBSD has been used as input for the simulations in this section. The RockGIS parameters have been adjusted so that the resulting RBSD, the centre of gravity of the deposit and the statistics of a control section resemble the field data.

In our work, the Digital Elevation Model used for the rockfall simulations has been elaborated using the "Institut Cartografic i Geològic de Catalunya" (ICGC) airborne laser scanning survey carried out in 2009.The aspect and slope raster maps needed for the simulation have been obtained from this Digital Elevation Model with a resolution of 1x1m. A coverage map has been elaborated from the regional data of "Centre de Recerca Ecologica i Aplicacions Forestals" (CREAF) with some manual adjustment to include local substrate coverage variations not observed at regional scale. This coverage map is used for assigning the restitution coefficient values to each coverage type.

To start the simulation of each block of the ISBD, several release points have been defined inside the estimated detachment area with an average elevation of $20 \mathrm{~m}$ above the ground to approximate the position of the real mobilized mass. The blocks of the IBSD are randomly associated to one of these release points each time a simulation is run. This procedure accounts for the uncertainty about the real position of each block at the time of the failure.

\subsection{Calibration}

The model requires the calibration of both the runout of the resultant blocks and the spatial distribution of the volumes of fragments generated by breakage during their propagation. As this is a coupled process, the adjustment has been made by varying the parameters affecting the propagation of the blocks, such as the coefficients of restitution and the parameters that define the breakage criterion (energy threshold limit, $b$ and $c$ coefficients for the breakage model and cone aperture). We made the restitution coefficients vary $15 \%$ beyond the mean values randomly in order to add stochasticity to the process in order to take into account local roughness variations and other uncertainties. The value of $15 \%$ was chosen to allow some variability of the trajectories between simulations while keeping all the parameters constant. This percentage was enough to avoid changing the overall performance of the simulation. 
We tested several sets of parameters. This was carried out by varying each parameter using fixed intervals and we selected the one that best fitted the field data using the following seven performance criteria:

- Position of the centre of gravity of the whole block distribution

- Histogram of the runout of the blocks

- Extent and boundaries of the YDC over the slope surface

- Lateral dispersion of trajectories

- Total number of blocks generated

- Volume distribution of the generated fragments

- The number of blocks and volume passages past a reference line (a forest road in the study area)

The final parameters selected after this process were a compromise which fit all the aforementioned criteria. The selected parameters are summarized in Table 1.

Table 1. Values of the parameters used for the five simulations performed in RockGIS.

\begin{tabular}{|c|c|c|c|c|c|c|c|c|}
\hline & $\mathrm{R}_{\mathrm{n}}[-]$ & $\mathrm{R}_{\mathrm{t}}[-]$ & $\mathrm{R}_{\mathrm{n}}, \mathrm{R}_{\mathrm{t}}$ variation & Ethershold [kJ] & $\mathrm{P}_{\mathrm{br}}[-]$ & c [-] & $\mathrm{b}[-]$ & $\theta\left[{ }^{\circ}\right]$ \\
\hline Forest & 0,2 & 0,4 & \multirow{3}{*}{$15 \%$} & \multirow{3}{*}{8000} & \multirow{3}{*}{0.7} & \multirow{3}{*}{0,02} & \multirow{3}{*}{1,0} & \multirow{3}{*}{$10^{\circ}$} \\
\hline Talus deposit & 0,37 & 0,5 & & & & & & \\
\hline Bare Rock & 0,52 & 0,7 & & & & & & \\
\hline
\end{tabular}

\subsection{Results}

In order to visualize the effect of the fragmentation qualitatively, we have first performed a simulation of a $100 \mathrm{~m}^{3}$ rockfall with and without fragmentation using the selected model parameters. Fig. 6 shows the results of these two simulations. Note that as the process is stochastic, the same initial impact produces different output trajectories each time the simulation is run. In the fragmentation case, first impacts with the ground are not energetic enough to reach the breakage energy threshold but when the topography allows the block to gain more speed during its flight phase, it is able to reach the threshold and breaks into several fragments. Some of these generated fragments also break during their propagation. As expected, fragmentation generates higher passing frequencies and reduces the size of the blocks and their runout. In this particular case, the biggest fragment obtained after the simulation was $7.24 \mathrm{~m}^{3}$, the runout of the centre of mass of the distribution was $262 \mathrm{~m}$ and the runout for the unbroken $100 \mathrm{~m}^{3}$ block was $631 \mathrm{~m}$. 


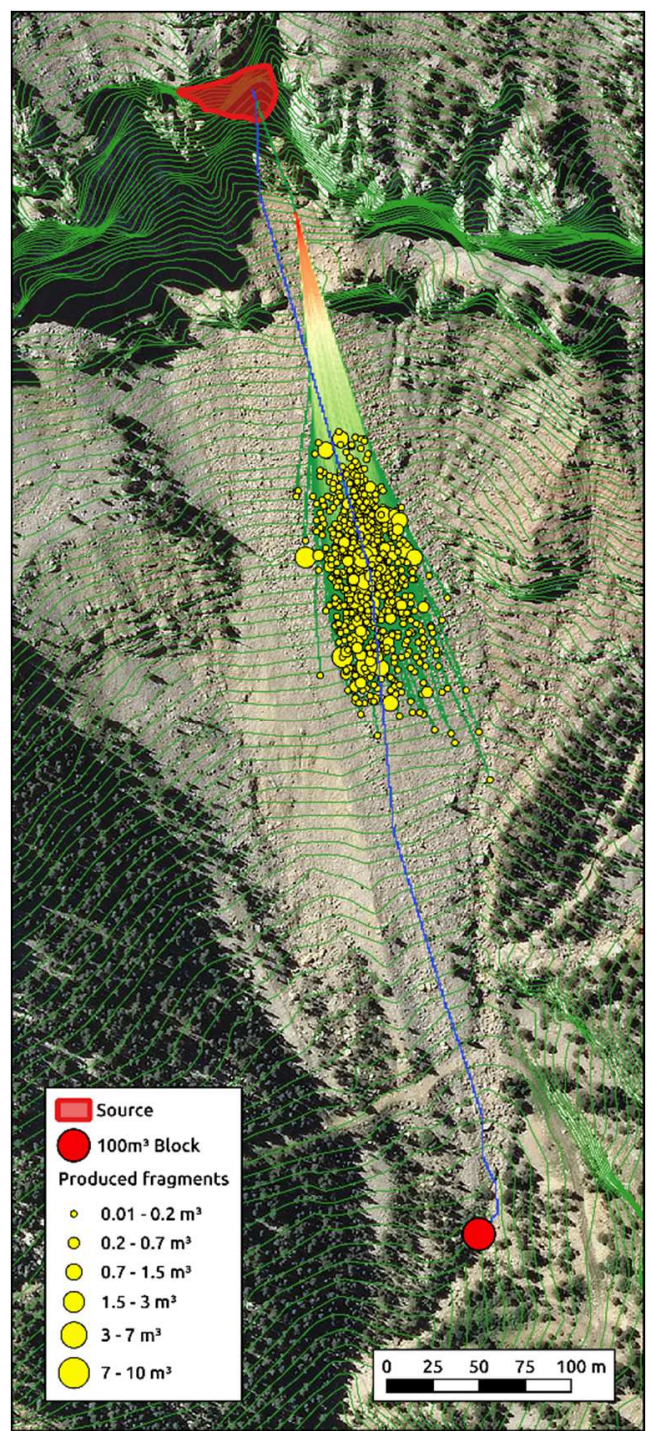

Fig. 6. Analysis of the propagation of a falling rock mass of $100 \mathrm{~m}^{3}$ with fragmentation (yellow circles scaled to their volume) and without it (red circle). The points show where the blocks stopped their propagation. In the fragmentation case, passing frequency is shown in a decreasing scale from red to green.

The event of Vilanova de Banat rockfall involving $10,000 \mathrm{~m}^{3}$ has been analyzed by means of five simulations considering fragmentation. The parameters of Table 1 were used allowing stochastic perturbations of the parameters and of the initial conditions. Five more simulations considering only the initial disaggregation of the ISBD were performed keeping the parameters affecting the propagation constant and disabling the breakage module to evaluate the influence of considering the breakage. Fig. 8 shows the locations where the propagation of the simulated blocks finished in two of the simulations run into RockGIS: without considering breakage in Fig. 8 left, considering it in Fig. 8 right, and the field data from Ruiz-Carulla (2015a) in the centre. The size of the circles is proportional to the volume of the block.

In the simulations where breakage was not considered the block size distribution did not change, hence the centre of gravity in terms of mass (c.o.g) of the distribution has a larger runout than in the simulations considering fragmentation where the volume of the blocks was reduced during the propagation. The simulations without breakage show an average increase in the c.o.g runout of $79 \mathrm{~m}$ with respect to the field c.o.g.

For a quantitative comparison of the results obtained by RockGIS, the location of the centre of gravity of the rockfall deposit generated in the five simulations considering fragmentation has been compared to the c.o.g. obtained by RuizCarulla (2015a) field inventory. The location of these c.o.g. can be appreciated in Fig. 7. The distances between the field c.o.g. and the simulated c.o.g. are 1.57, 1.18, 2.82, 2.36 and 5.67 meters for simulations 1 to 5, respectively. 


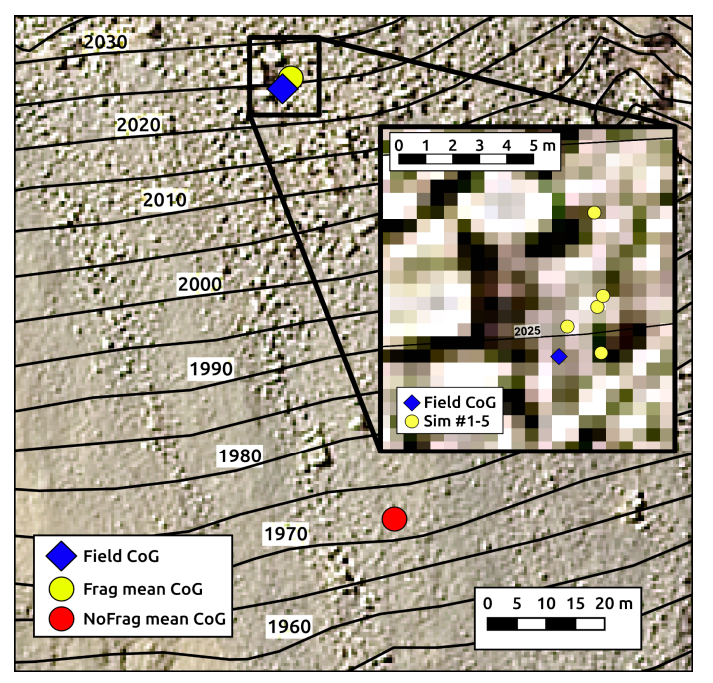

Fig. 7. Vilanova de Banat Rockfall: Mean location of the centre of gravity in terms of the mass of the rockfall deposit generated in the five RockGIS simulations with breakage (red circle) and without it (yellow circles) and the centre of gravity obtained by Ruiz-Carulla (2015a) field inventory (blue square). The zoom shows the exact location of each centre of gravity of the five simulations considering breakage.

In Fig.8 left it can be observed that the maximum runout of the simulated blocks is similar to what was observed in the field. The lateral spreading of the block trajectories is also similar. The LSB accumulation of the inventory on the depression corresponds to blocks that ended their propagation rolling, following the maximum slope path. This accumulation is only barely observable in the simulation results since pure rolling is not actually implemented in the current version of RockGIS.

For the proper visualization of the accumulation of the simulated blocks that have reached the end of their propagation, a set of polygons containing specific percentages with respect to the total amount of simulated blocks has been calculated. Fig. 9 shows the results of this procedure overlaid with the field data. It is observed that the YDC perimeter is quite similar to the contour of the polygon containing $80 \%$ of the simulated blocks. Moreover, most of the LSB remain inside the $99 \%$ polygon. In this density analysis the simulated blocks with the largest runout cannot be observed as they are not quantitatively representative relative to the total amount of simulated blocks (less than $1 \%$ ). 

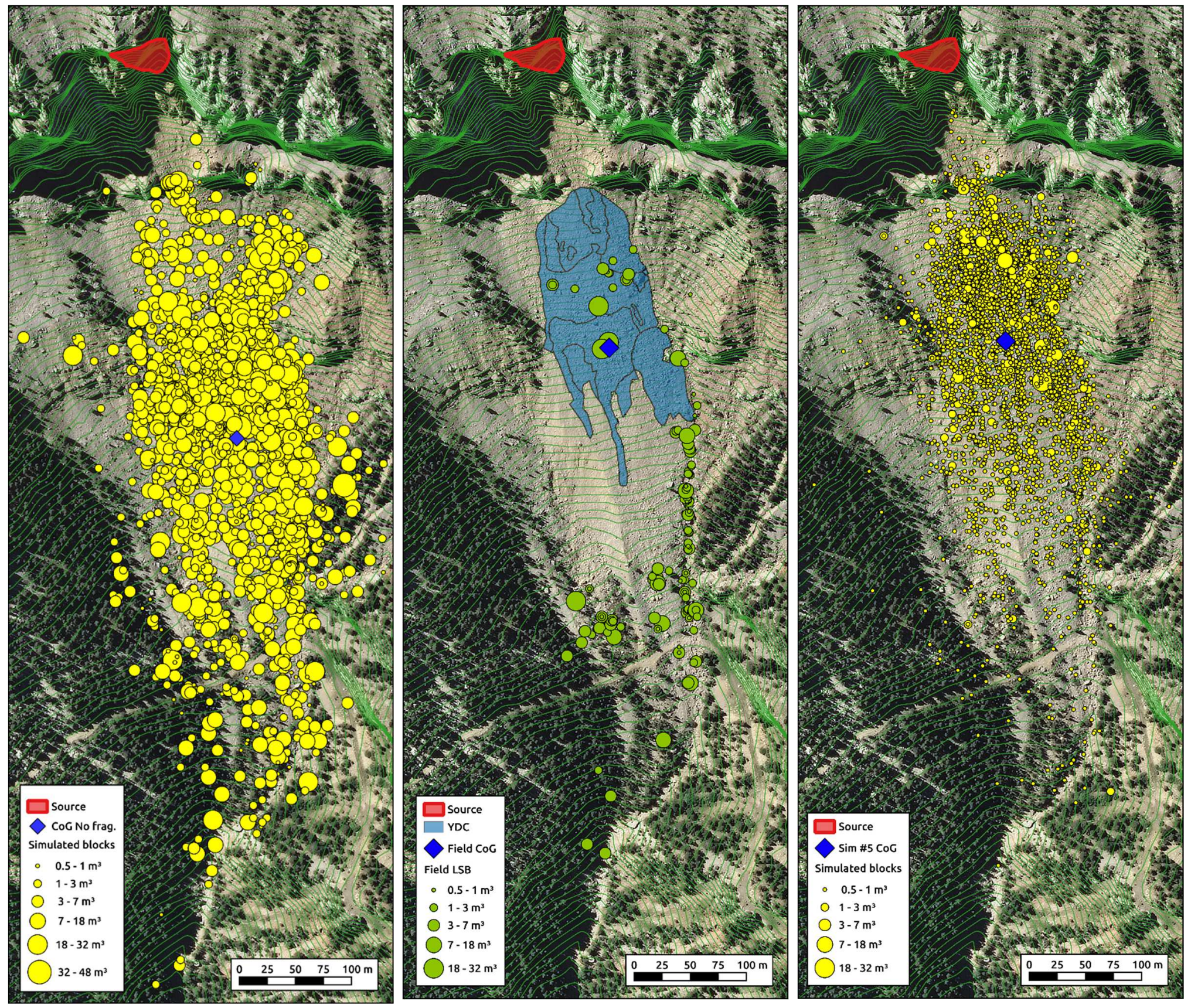

Fig. 8. Final position of the blocks obtained with RockGIS model with fragmentation (right) and without it (left) in one of the five simulations performed in each case (\#1 without fragmentation and \#5 with fragmentation). Small blocks (0.5 $\mathrm{m}^{3}$ ) have been hidden for better visualization. Field data from RuizCarulla et al. (2015a) is shown in the central image. 


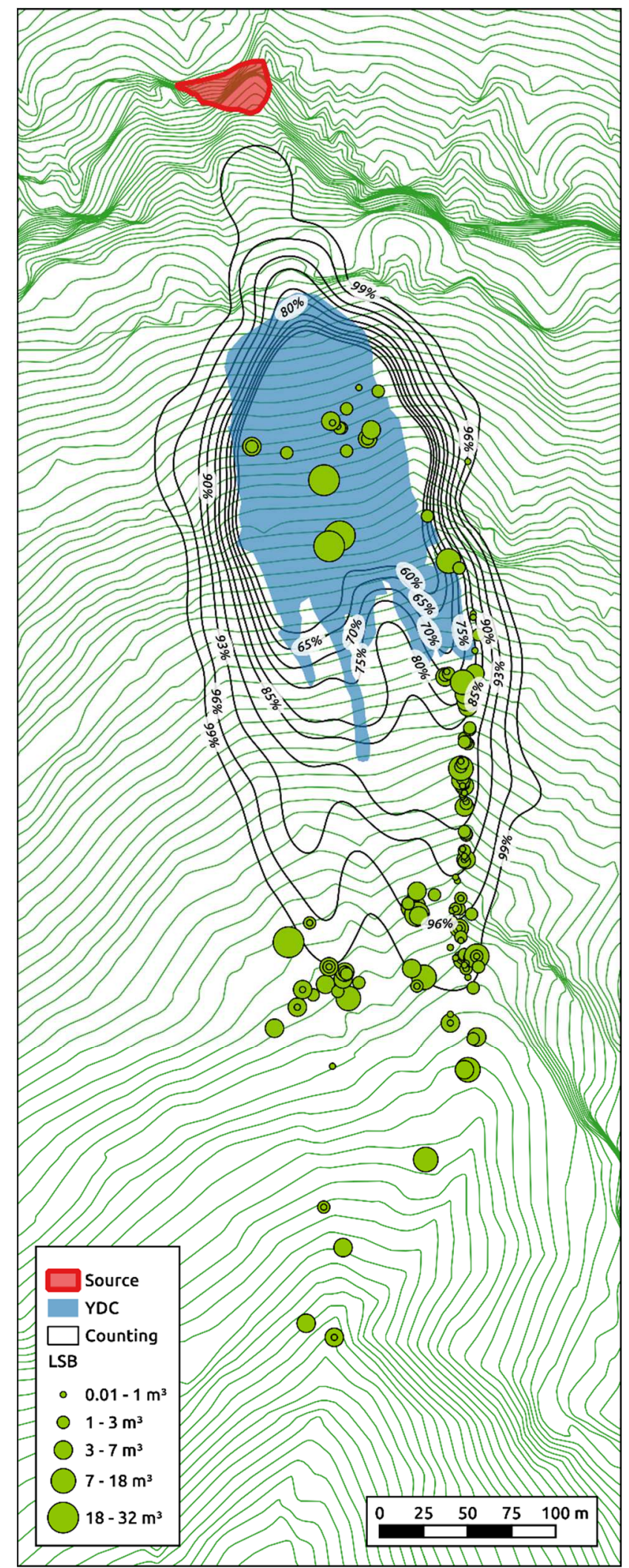

Fig. 9. Density map of the accumulated blocks of simulation \#5 considering fragmentation superposed with the field YDB and LSB measured by Ruiz-Carulla et al. (2015a). Contour lines represent the percentage of the blocks that stopped within the corresponding polygon.

In order to compare the runout distances obtained with RockGIS with those observed in the field, some assumptions had to be made. Field data provide an approximation of the total number of blocks and their volumes for each YDC sub-area considered during the inventory characterized by its correspondent sampling plot, but not individual information of the runout for each individual block. All blocks inside each YDC area have been supposed to have the same runout 
corresponding to the distance from the centroid of their YDC polygon to the centroid of the source area. Fig. 10 shows a comparison between field runout histograms and the resultant histogram of the five simulation considering fragmentation. It should be noted that the runout range of the field data has been underestimated as all blocks had to be assumed to have the same runout (the centroid of the corresponding YDC polygon). This could explain why in this Fig. more runout is observed in the simulation histogram. It is also important to consider that the simulations generated a mean of 84584 blocks while the measurement of the RBSD estimated a total of 60066 . This difference may be due to the generation of small fragments which could not be measured in the field but which are included in the simulations.

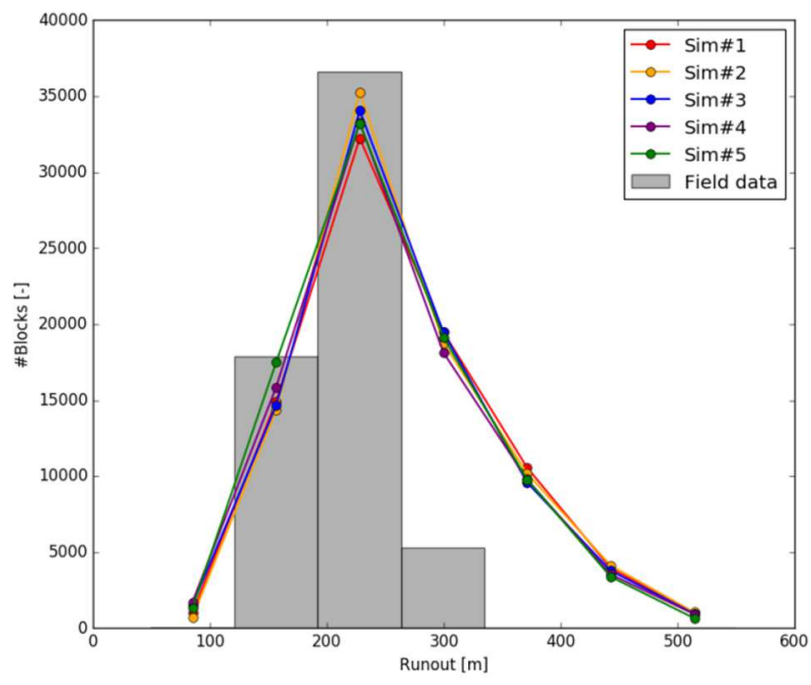

Fig. 10. Comparison between runout histograms of field data and the five simulations performed considering fragmentation.

In Fig. 10 the effect of the LSB on the total distribution is underestimated as they represent a mere $0.45 \%$ of the total amount of estimated blocks of the RBSD. To see the correspondence of the LSB runout with the simulation results, Fig. 11 shows the runout distances against the volume of the blocks observed in the field and simulated. From this Fig. it can be concluded that the model tends to overestimate the volume of the LSB but it is able to provide an accurate estimation of the spatial distribution of their runout distances. Note that just the LSB are shown in Fig. 11 as the field data does not provide the position of all blocks inside the YDC. 

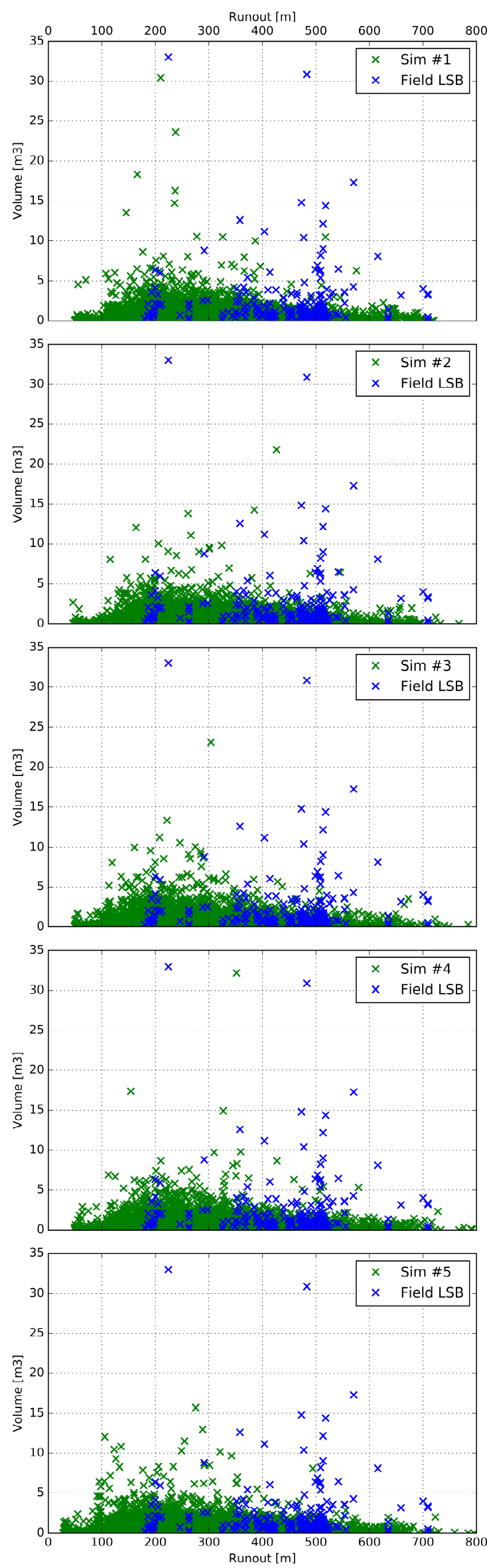

Fig. 11. Volume against runout of all the simulated blocks of the five simulations performed considering fragmentation against the LSB from field data. 
To have another quantitative measurement of the runout accuracy obtained with the proposed model, the simulated blocks that have crossed the forest road in the lower part of the study area have been counted and compared to the field data. Fig. 12 shows the blocks which came to a stop below the forest road in the five simulations performed and the field data. In Table 2 the numerical results of this analysis are presented.

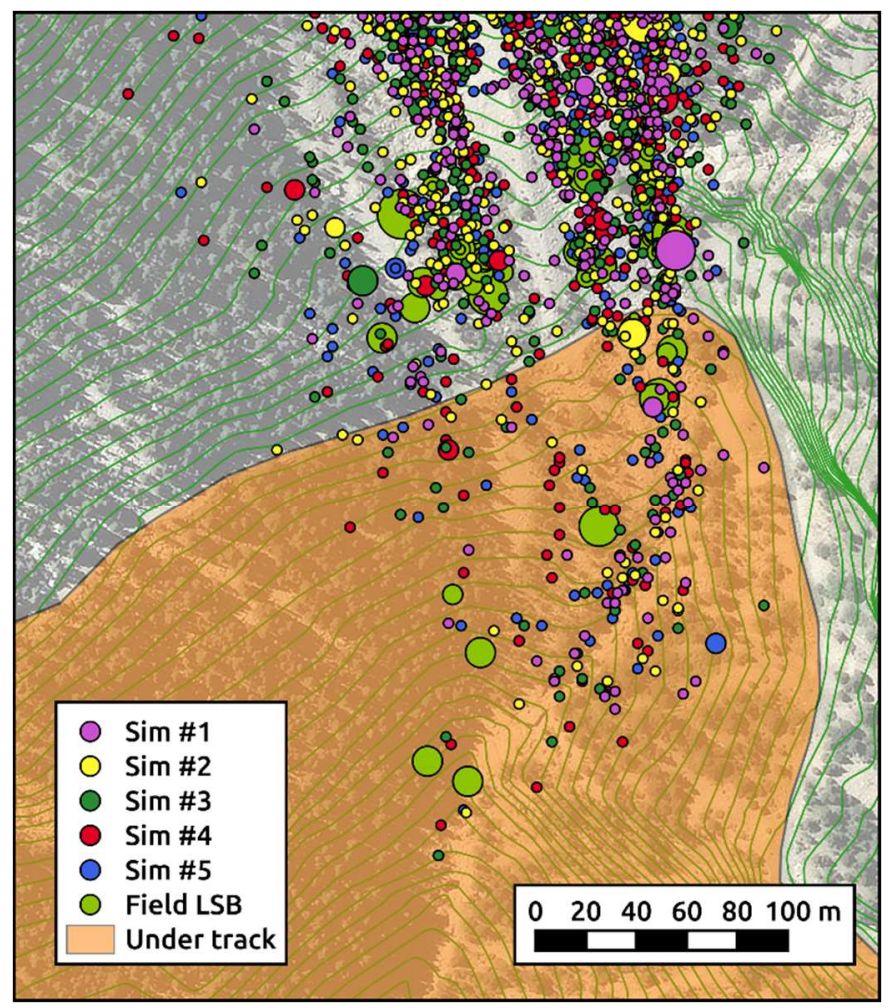

Fig. 12. Stopping points of simulated blocks with a volume greater than $0.5 \mathrm{~m}^{3}$ and LSB measured in the field. The orange area is the forested area used for the calculations shown in Table 2.

Table 2. Statistics of the blocks inventoried in the field crossing the forest track and of the five simulations performed. Crossing blocks over the total number of generated blocks and inventoried blocks give the percentage of blocks crossing the forest road. The cumulative volume of crossing blocks is compared to the field inventory in column "Vol.Variation \%".

\begin{tabular}{|c|c|c|c|c|c|c|}
\cline { 2 - 7 } \multicolumn{1}{c|}{} & $\begin{array}{c}\text { Total } \\
\text { crossing \# }\end{array}$ & $\begin{array}{c}\text { Crossing \# } \\
>0.5 \mathrm{~m}^{3}\end{array}$ & Total blocks & $\begin{array}{c}\text { Crossing \%o } \\
>0.5 \mathrm{~m}^{3}\end{array}$ & Crossing vol. [m3] & Vol. Variation \% \\
\hline Field & - & 25 & 60066 & 0.42 & 64.9 & - \\
\hline Sim\#1 & 261 & 46 & 83416 & 0.55 & 71.1 & 9.6 \\
\hline Sim\#2 & 222 & 34 & 84683 & 0.40 & 60.7 & -6.5 \\
\hline Sim\#3 & 252 & 47 & 85203 & 0.55 & 69.9 & 7.7 \\
\hline Sim\#4 & 313 & 55 & 84304 & 0.65 & 78.6 & 21.0 \\
\hline Sim\#5 & 189 & 38 & 83511 & 0.46 & 58.2 & -10.4 \\
\hline
\end{tabular}

The total number of blocks greater than $0.5 \mathrm{~m}^{3}$ and the total accumulated volume of blocks which crossed the forest road in the simulations are very similar to those measured in the field. During the realization of the field inventory (Ruiz-Carulla et al. 2015a) the smallest blocks outside the YDC were not measured and only the blocks greater than 0.5 $\mathrm{m}^{3}$ were measured in general. This may explain the differences in the total number of blocks past the forest road between the field data and the simulations (where small blocks are taken into account).

Fig. 13 shows the five RBSD (cumulative frequency curves) obtained by RockGIS simulations considering fragmentation against the field RBSD and IBSD. The resultant RBSD is largely similar in the five simulations run. They very nearly coincide in the domain corresponding to the power law used for distributing the mass of the fragments during breakage (with $c=0.02$ and $b=1$ ) but differ slightly in the part of the curve representing the greatest volumes. This can be explained by the stochasticity of the process for generating the fragments and the energy threshold for triggering breakage. In a simulation, a block may break into smaller fragments than the same block in same impact conditions in other simulations. 


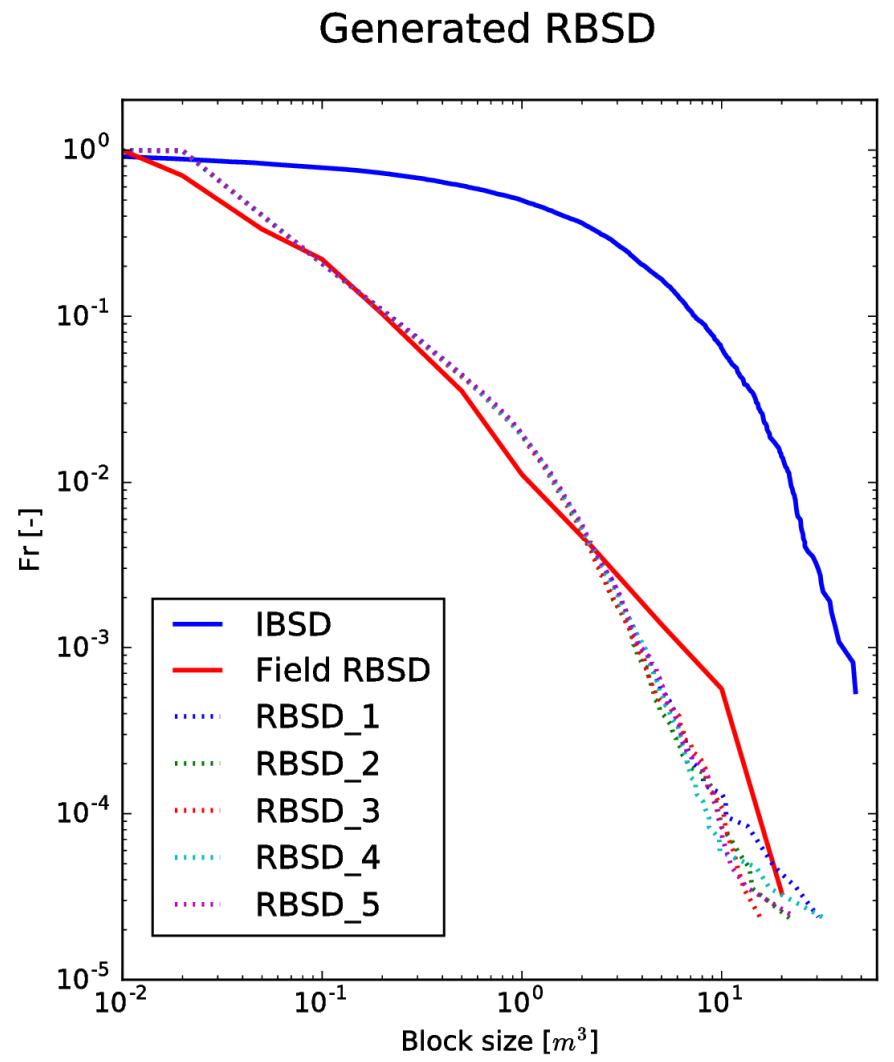

Fig. 13. RBSD obtained from five simulations in RockGIS against field data RBSD. The IBSD measured in the field is the same used for the simulations. Both axes are in logarithmic scale.

To see the response of the fragmentation model to some of its important parameters, we performed simulations varying the angle of the cone $\theta$ and parameter $b$, keeping constant all the parameters obtained with the calibration process. For the cone we chose $10^{\circ}, 20^{\circ}, 40^{\circ}$ and $60^{\circ}$ apertures. The location of the c.o.g and the line defining the area containing $80 \%$ of the deposited blocks for each case are shown in Fig. 14.

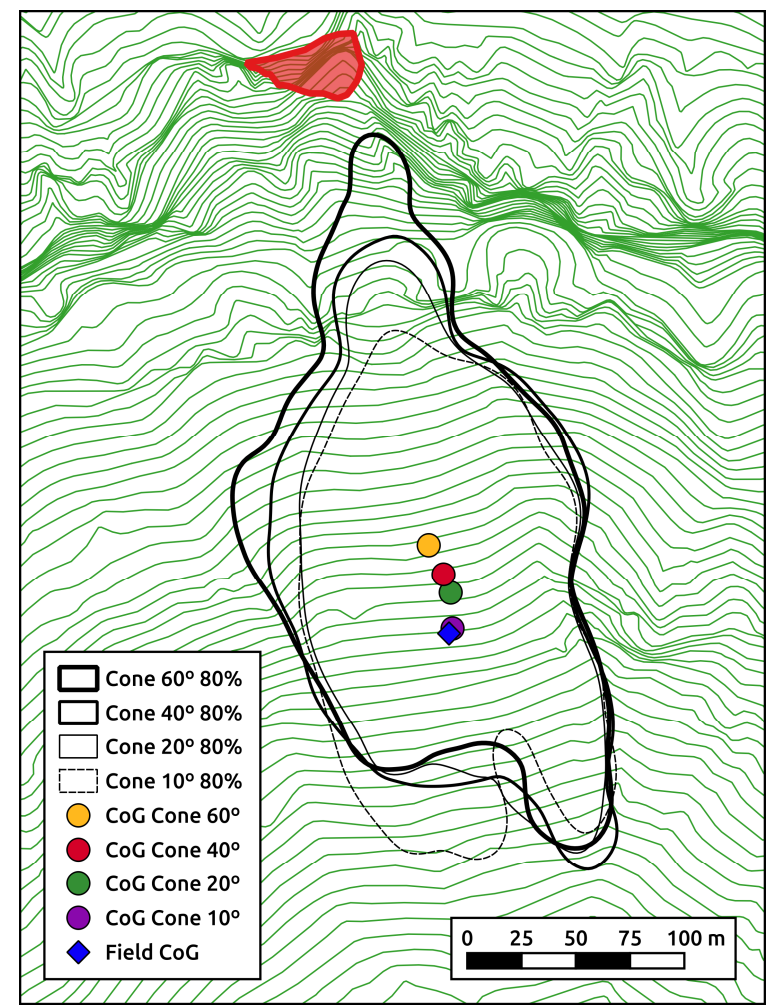


Fig 14. Density map of the accumulated blocks of four simulations varying the angle of the cone $(\theta)$ and their centre of gravity. Contour lines represent the percentage of the blocks that came to a stop within the corresponding polygon.

To appreciate the influence of parameter $b$, five simulations were performed considering values $0.5,0.75,1.0,1.25$, and 1.5. Fig. 15 shows the cumulative number of blocks of each obtained RBSD. An inflexion point can be observed due to the slope variation of the power law. In this figure the limitation of the model to generate a maximum volume of fragments each time breakage occurs depends on parameter $b$ (see Equation 6). Note that the results with $b$ equal to 0.75 seem to fit the field RBSD better, but the total number of blocks generated in this case was 125167, which represents more than double the estimated number of blocks in the field; additionally, during the calibration phase with $b$ equal to 0.75 , the other calibration criteria gave unsatisfactory results.

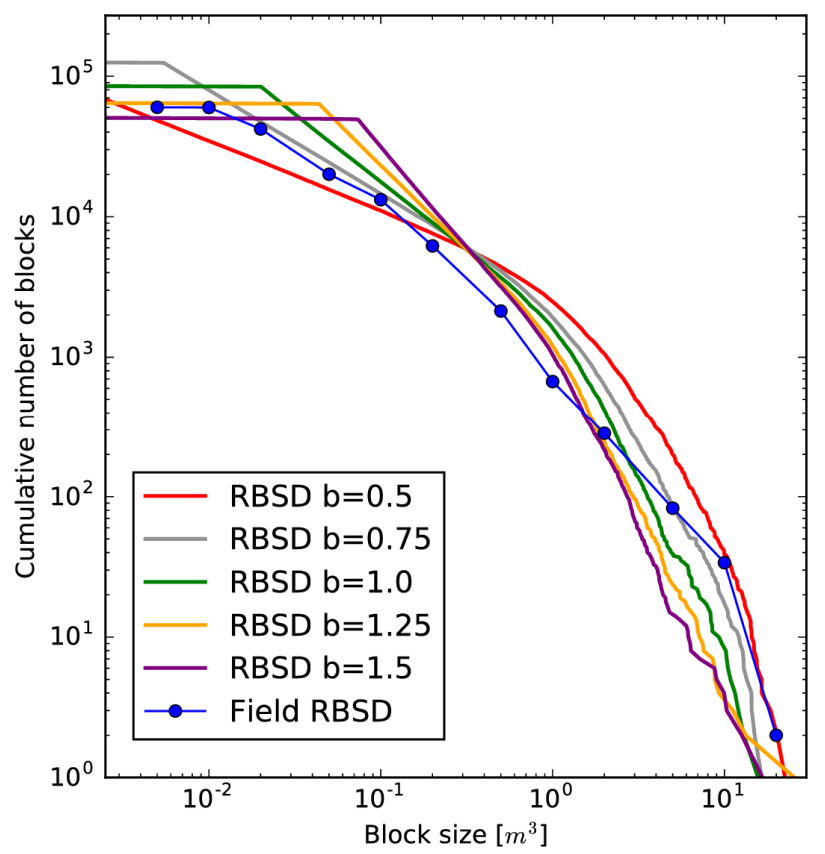

Fig 15. Cumulative number of blocks of the five simulations performed keeping all the parameters constant except the slope of the power law $b$ (Equation 5).

\section{DISCUSSION}

The capability of the RockGIS model to calculate the trajectories of blocks accurately relies on the resolution of the input parameters such as the Digital Elevation Model or the accuracy of the land-use cover (Van Westen et al. 2008). For this work a resolution of $1 \times 1 \mathrm{~m}$ has been used. The trajectories can be modelled according to the resolution of the DEM, and the accuracy of the impacts and redirections depend on the pixel/cell size.

The model has shown a high sensitivity to the fragmentation process. The simulation of the fall of a $100 \mathrm{~m}^{3}$ rock mass has nicely shown that without fragmentation the unbroken block is able to cover longer distances and develop higher impact energies. The breakage results in a high number of smaller blocks, with divergent trajectories, shorter runout distances, and lesser kinetic energies. These effects are less evident in the failure of large rock masses characterized by an ISBD as in the case of Vilanova de Banat. As some blocks do not break during the propagation, runout distances for the modelling with and without fragmentation are similar. However, the number of large blocks reaching the lowest parts of the slope is reduced significantly with the fragmentation and the whole debris mass remains closer to the rock wall as shown by the locations of the centres of gravity.

The uncertainties of the input parameters affect the modelling results as one would expect. There are two categories of uncertainties: those associated with the spatial resolution of the data (cell size, etc.) and those associated with the limitations of our modelling (for instance, roughness is assumed constant for each land cover, the coefficient of restitution is a quite simple approach, the breakage mechanism is still poorly understood, etc.). Several tests have shown that breakage of the blocks cannot be characterized by a single parameter such as the impact kinetic energy. Other factors such as the rigidity of the ground, angle of impact, rock strength, presence of fissures in the block etc. may strongly affect the results. However, the simple assumption of an energy threshold that triggers breakage has shown to be useful for modelling purposes when considering fragmentation, but the model needs further calibration based on additional cases with different lithology and slope conditions. 
The model uses the lumped mass approach whose restrictions are already known: it does not explicitly take into account the shape of the blocks, their rotational movement or the relative position of the internal fractures of a block with respect to the impacting angle. In this study we have focused on the fragmentation of the blocks and the use of power laws to represent the volumetric distributions after breakage, and lumped mass approach has allowed us to deal easily with mass distribution after breakage. With this approach we avoid having to determine the shape of each generated fragment, which would require a great deal of computational time in a rigid body approach. Other rebound algorithms that take into consideration these factors will be tested in future works to determine if we can better reproduce the larger runout of the biggest generated fragments observed in the field.

Despite these limitations, the RockGIS model has been able to reproduce the 2011 rockfall event of Vilanova de Banat in Sierra del Cadí. Seven criteria have been used to check the performance of the five simulations, more than the criteria normally used to calibrate such rockfall models. The fulfilment of these criteria makes the calibration process a delicate exercise that ends with a compromise between them.

The model has been able to approach the position of the centre of gravity of the whole distribution with an average error of $2.72 \mathrm{~m}$ in the five simulations considering fragmentation. The runout histograms obtained tend to overestimate the number of blocks reaching higher runouts, but the mean field runout around $250 \mathrm{~m}$ fits well with the field data. This may be due to the incompleteness of the field inventory since small blocks which could not be measured are nevertheless taken into account in the simulation. The extend boundaries of the YDC matched the polygon containing $80 \%$ of the blocks in the performed simulations, whilst the polygon containing $96 \%$ of the blocks had an average lateral divergence of $23 \mathrm{~m}$ (see Fig. 9). The mean number of blocks generated in the simulations was 84223 , which is $40 \%$ higher than the number measured in the field. It is worth noting that the several assumptions that had to be made when estimating the number of blocks in the field, such as the depth of the YDC and the minimum measured block volume, may lead to an underestimation of the number of blocks. The volume distributions obtained in the five simulations fitted reasonably well with the field data (Fig. 13); the dispersion in the right tail is explained by the stochasticity of the process.

When varying parameters $\theta$ and $b$, the model performed as expected. Increasing the angle of the cone produced higher lateral dispersion and, consequently, the c.o.g. of the distribution approached the source area since the blocks lost much more energy upon impact with the lateral topographic constraints of the case study. By increasing parameter $b$, the number of blocks generated during each breakage, the total number of generated blocs and the slope of the resultant power law increased, as expected. Parameter $b$ is one of the most complex to adjust since it modifies both the volumetric distribution and the total number of generated blocks.

Using power laws to distribute the mass has proven to be a simple way of representing the breakage process. However, the power law as implemented in the present work has the limitation of being only able to generate a fixed minimum fragment size which depends on the selected parameters $c$ and $b$ (see Equation 6). The implementation of more complex fractal distribution laws for fragmentation (such as the one presented in Ruiz-Carulla et al., 2016a) may allow an easier control of the number and volumetric distribution of the generated blocks. However, the problem of breakage triggering will still remain unsolved; thus, when using the lumped mass approach, simple assumptions (such as the breakage energy threshold) will still be needed.

We expect that, with the analysis of further rockfall events, we will be able to recommend a range of values for the model parameters taking into account the conditions of the slope.

The consequences of the fragmentation are important for the rockfall hazard and risk analysis. This is particularly evident for small-sized rockfalls $\left(10-1000 \mathrm{~m}^{3}\right)$ in which fragmentation causes the generation of a large number of small blocks with divergent trajectories but with shorter runout distances and lesser kinetic energies. This may affect the boundaries of the areas threatened by rockfalls, the design of protection measures and the elaboration of hazard maps.

The model runs in a GIS environment. The computing time for a simulation on a common desktop computer was between 3 and 4 minutes in cases without fragmentation (approximately 3000 blocks of the IBSD), and between 30 and 40 minutes when the fragmentation was considered (actual time depends on the number of fragments generated). Prior to the simulations, the geometry (Digital Elevation Model) and other site data required (coverage map, for instance) must be loaded into the model, the required time being about 1.5 minutes.

The reliability of the input data affects the quality of the modelling. For the detachment of large rock masses, knowledge of IBSD is required. The procedures for obtaining the ISBD are still in their infancy, but the availability of modern tools for data capture (Terrestrial Laser Scanning - TLS -, digital photogrammetry - both terrestrial and UAV-, for instance) helps in this goal.

\section{CONCLUSIONS}

We have presented a stochastic modelling approach for considering fragmentation in rockfalls and implemented this methodology in the rockfall simulation code RockGIS. This GIS-based code simulates the propagation of the blocks using a lumped mass approach in the space defined by a Digital Elevation Model and performs the rebound calculations using restitution factors according to the land cover. 
To analyze the fragmentation process, disaggregation of the unstable rock mass through pre-existing discontinuities is considered before the propagation by simulating each block of the In Situ Block Size Distribution individually. During the propagation, on each impact of a block with the ground a breakage module is applied with the following key characteristics: (i) an energy threshold is used as the breakage criterion in an impact with the ground; (ii) when breakage occurs, an additional amount of energy is lost; (iii) the generation of fragments and distribution of mass after breakage is done stochastically following a power law; (iv) the remaining energy is distributed between all the fragments proportionally to their mass; (v) the post-impact trajectories of each fragment are stochastically distributed within a cone. We calibrated the model against an inventory of a real rockfall near Vilanova de Banat village in Spain (RuizCarulla, et al., 2015a). It includes the position and volume of all the Large Scattered Blocks produced and an approximation of the total blocks and their volumes in the Young Debris Cover by means of sampling extrapolation. This calibration considered both the runout of the blocks and the Rockfall Block Size Distribution (RBSD) obtained and keeping all the parameters constant, five simulations were performed to check the variability in the results due to the stochasticity of the model. All the simulations gave similar results.

The proposed fragmentation model functions successfully and accomplishes the goal of representing the fragmentation process as we were able to reproduce the runout of the blocks and the RBSD measured in the field reasonably accurately. The model tends to underestimate the runout of big blocks as the simulated fragments with larger runout have lower volumes than the inventoried ones. The number of blocks crossing the forest road used for validation was overestimated in the simulations, but the total volume of the blocks crossing the forest road was similar to the field data $(-10 \%$ to $+21 \%)$. This overestimation may be explained by the incompleteness of the inventory as the smallest blocks outside the YDC were not measured.

Future work will include testing the model on other real rockfall events and performing more real scale tests to improve the mass and energy distribution algorithms used in the fragmentation model. These improvements will allow an approximate guess of the parameters that have to be used in the fragmentation model depending on the variables that affect the process, such as the rock material and the coverage. 


\section{REFERENCES}

Agliardi F, Crosta GB (2003) High resolution three-dimensional numerical modelling of rock falls. Int. J. Rock Mech. Min. Sci., 40/4: 455-471.

Bourrier F, Eckert N, Nicot F, Darve F (2009) Bayesian stochastic modeling of a spherical rock bouncing on a coarse soil. Natural Hazards and Earth Systems Sciences, 9: 831-846. doi:10.5194/nhess-9-831-2009.

Bourrier F, Hungr O (2011) Rockfall dynamics: a critical review of collision and rebound models. In: Lambert S, Nicot F (eds) Rockfall engineering ISTE Ltd and John Wiley and Sons Inc: 175-203. doi:10.1002/9781118601532.ch6.

Corominas J (2013) Avoidance and Protection Measures. In: Shroder JF (ed) Treatise on Geomorphology,7: $259-272$. San Diego: Academic Press.

Corominas J, Mavrouli O, Santana D, Moya J (2012) Simplified approach for obtaining the block volume distribution of fragmental rockfalls. In: Eberhardt E, Froese C, Turner AK, Leroueil S (eds) Landslides and engineered slopes, 2: 1159-116.

Crosta GB, Agliardi F (2003) A methodology for physically based rockfall hazard assessment. Natural Hazards and Earth System Sciences 3: 407-422.

Cruden DM, Varnes DJ (1996) Landslide types and processes. In: Turner AK, Schuster RL (eds) Landslides: investigation and mitigation, transportation research board special report, 247: 36-75. National Research Council, USA.

Cuervo S (2015) Modélisation des éboulements rocheux par la méthode des éléments discrets: application aux évènements réels. Dissertation, Université de Grenoble. Retrieved from www.theses.fr/2015GREAI066.pdf

Dorren LKA, Berger F, Hir C, Mermin E, Tardif P (2005) Mechanisms, effects and management implications of rockfall in forests. Forest Ecology and Management, Volume 215, Issues 1-3: 183-195. ISSN 0378-1127, http://dx.doi.org/10.1016/j.foreco.2005.05.012.

Dupire S, Bourrier F, Monnet JM, Bigot S, Borgniet L, Berger F, Curt T (2016) Novel quantitative indicators to characterize the protective effect of mountain forests against rockfall. Ecological Indicators, 67: 98-107. ISSN 1470160X, http://dx.doi.org/10.1016/j.ecolind.2016.02.023.

Evans S, Hungr O (1993) The assessment of rockfall hazard at the base of talus slopes. Canadian Geotechnical Journal 30: pp 620-636.

Ferrari F, Giacomini A, Thoeni K (2016) Qualitative Rockfall Hazard Assessment: A Comprehensive Review of Current Practices. Rock Mechanics and Rock Engineering: 1-58. DOI 10.1007/s00603-016-0918-Z

Fornaro M, Peila D, Nebbia M (1990) Block falls on rock slopes - application of a numerical simulation program to some real cases. Proceedings of the 6th International Congress IAEG. Rotterdam: Balkema: 2173-80.

Frattini P, Crosta GB, Agliardi F (2012). Rockfall characterization and modeling. In: Clague JJ; Stead (eds) Landslides Types, mechanisms and modeling. p. 267-281, Cambridge University Press, ISBN: 978-1-107-00206-7

GeoRock3D® (GeoStru Software): Commercial rockfall analysis software. http://www.geostru.com/en/rock-falls3d.aspx

Giacomini A, Buzzi O, Renard B, Giani G (2009) Experimental studies on fragmentation of rock falls on impact with rock surfaces. International Journal of Rock Mechanics and Mining Sciences 46: 708-715.

Giacomini A, Thoeni K, Lambert C, Booth S, Sloan SW (2012) Experimental study on rockfall drapery systems for open pit highwalls. International Journal of Rock Mechanics and Mining Sciences, Volume 56: 171-181, ISSN 13651609, http://dx.doi.org/10.1016/j.ijrmms.2012.07.030.

Gili JA, Ruiz R, Matas G, Corominas J, Lantada N, Núñez MA, Mavrouli O, Buill F, Moya J, Prades A, Moreno S (2016) Experimental study on rockfall fragmentation: in situ test design and firsts results. In: Aversa S, Cascini L, Picarelli L, Scavia C (eds) Landslides and engineered slopes, 2: 983-990.

Gischig V, Hungr O, Mitchell A, Bourrier F (2015) Pierre3D: a 3D stochastic rockfall simulator based on random ground roughness and hyperbolic restitution factors. Canadian Geotechnical Journal 52: 1-14.

Grady DE, Kipp ME (1987) Dynamic rock fragmentation. In: Atkinson BK (ed) Fract Mech Rock, 17. London: Academic Press.

Hantz D, Rossetti JP, Servant F, D’Amato J (2014) Etude de la distribution des blocs dans un éboulement pour l'évaluation de l'aléa. Proceedings of Rock Slope Stability 2014, Marrakesh. 
Hoek E (2000) Analysis of rockfall hazards. In: Hoek E (ed) Practical rock engineering: 117-136.

Hungr O, Leroueil S, Picarelli L (2014) The Varnes classification of landslide types-an update. Landslides, 11: 167194. doi:10.1007/s10346-013-0436-y.

Lambert S, Bourrier F, Toe D (2013) Improving three-dimensional rockfall trajectory simulation codes for assessing the efficiency of protective embankments. International Journal of Rock Mechanics and Mining Sciences 60: 26-36. ISSN 1365-1609, http://dx.doi.org/10.1016/j.ijrmms.2012.12.029.

Lan H, Derek Martin C, Lim CH (2007) RockFall analyst: a GIS extension for three-dimensional and spatially distributed rockfall hazard modeling. Computer Geoscience 33(2): 262-279

Leine RI, Schweizer A, Christen M, Glover J, Bartelt P, Gerber W (2013) Simulation of rockfall trajectories with considerationof rock shape. Multibody Syst Dyn. DOI 10.1007/s11044-013-9393-4

Li L, Lan H (2015) Probabilistic modeling of rockfall trajectories: a review. Bulletin of Engineering Geology and the Environment 1: 1-14.

Mancini R, Del Greco O, Fornaro M, Patrucco M. (1981) Indagine sperimentale sullabbattimento meccanico delle rocce mediante martelli demolitori di medio peso. Bollettino dell Associazione Mineraria Subalpina: 88-102.

Meissl G (1998) Modellierung der Reichweite von Felsstüurzen: Fallbeispiele zur GIS-gestützten Gefahrenbeurteilung, Dissertation, Institut fur Geographie. Univ. Innsbruck.

Moya J, Corominas J, Mavrouli O (2013). A geomorphologic and probabilistic approach to the number and size of blocks of fragmental rockfalls, 8th IAG International Conference on Geomorphology, Paris. Abstracts volume: 660.

Paluszny A, Tang XH, Nejati M, Zimmerman RW (2016) A direct fragmentation method with Weibull function distribution of sizes based on finite and discrete element simulations. International Journal of Solids and Structures, 80: 38-51. ISSN 0020-7683, http://dx.doi.org/10.1016/j.ijsolstr.2015.10.019.

di Prisco, C, Vecchiotti, M (2006). A rheological model for the description of boulder impacts on granular strata. Géotechnique 56, No. 7, 469-482, http://dx.doi.org/10.1680/geot.2006.56.7.469

Ritchie AM (1963) Evaluation of rockfall and its control. Highway research board record, 17, Washington.

RockPro3D@ (Geociel): Commercial rockfall analysis software. http://www.rocpro3d.com/rocpro3d_fr.php

Ruiz-Carulla R, Corominas J and Mavrouli O (2016a) A fractal fragmentation model for rockfalls. Landslides doi:10.1007/s10346-016-0773-8

Ruiz-Carulla R, Corominas J, Mavrouli O (2016b) Comparison of block size distribution in rockfalls. In: Aversa S, Cascini L, Picarelli L, Scavia C (eds) Landslides and engineered slopes, 3: 1767-1774.

Ruiz-Carulla R, Corominas J, Mavrouli O (2015a) A methodology to obtain the block size distribution of fragmental rockfall deposits, Landslides, 12 (4): 815-825.

Ruiz-Carulla R, Corominas J, Mavrouli O (2015b) An empirical approach to rockfall fragmentation. EUROCK 2015 \& 64th Geomechanics Colloquium, Schubert (ed): 151-156.

Salciarini D, Tamagnini C, Conversini P (2009) Numerical approaches for rockfall analysis: A comparison. Proceedings of 18th IMACS world congress/MODSIM09: 2706-2712. Cairns.

Van Dijke J, van Westen C (1990) Rockfall hazard: a geomorphological application of neighbourhood analysis with ILWIS. ITC Journal, 1: 40-44.

Van Westen CJ, Castellanos E, Kuriakose SL (2008) Spatial data for landslide susceptibility, hazard, and vulnerability assessment: an overview. Engineering geology 102 (3), 112-131.

Volkwein A, Schellenberg K, Labiouse V, Agliardi F, Berger F, Bourrier F, Dorren LKA, Gerber W, Jaboyedoff M (2011) Rockfall characterisation and structural protection - a review. Natural Hazards and Earth System Science, 11: 2617-2651.

Wang Y, Tonon F (2011) Discrete Element Modeling of Rock Fragmentation upon Impact in Rock Fall Analysis. Rock Mechanics and Rock Engineering, 44: 23-35.

Zhang ZX, Kou SQ, Jiang LG, Lindqvist PA (2000) Effects of loading rate on rock fracture: fracture characteristics and energy partitioning. Int J Rock Mech Min Sci, 37: 745-62. 